Journal Article

\title{
Domestic demand-side management: Analysis of microgrid with renewable energy sources using historical load data
}

Hecht, C., Sprake, D., Vagapov, Y. and Anuchin, A.

This article is published by Springer. The definitive version of this article is available at: https://link.springer.com/article/10.1007/s00202-020-01197-y

\section{Recommended citation:}

Hecht, C., Sprake, D., Vagapov, Y. and Anuchin, A. (2021), 'Domestic demand-side management: Analysis of microgrid with renewable energy sources using historical load data', Electrical Engineering, published online 10 January 2021. doi: 10.1007/s00202-020-01197-y. Available at: https://link.springer.com/article/10.1007/s00202-020-01197-y 


\title{
Domestic Demand-Side Management: Analysis of Microgrid with Renewable Energy Sources using Historical Load Data
}

\author{
Christian Hecht ${ }^{1}$, David Sprake ${ }^{1}$, Yuriy Vagapov ${ }^{1, *}$ and Alecksey Anuchin ${ }^{2}$ \\ ${ }^{1}$ Faculty of Art, Science and Technology, Wrexham Glyndwr University, Plas Coch, Mold Road, Wrexham, \\ LL11 2AW, UK \\ ${ }^{2}$ Department of Electric Drives, Moscow Power Engineering Institute, 14 Krasnokazarmennaya Street, 111250 , \\ Moscow, Russia \\ *Correspondence: y.vagapov@glyndwr.ac.uk (http://orcid.org/0000-0002-2992-1482)
}

\begin{abstract}
This paper provides a high accuracy assessment of domestic demand-side management (DSM) approach in the context of distributed renewable energy sources (RES). To determine the potential of domestic DSM for households, a microgrid model of a typical UK residential estate was developed to simulate the impact of RES. The microgrid model comprises of $15 \mathrm{UK}$ households with appropriate allocation of washing machines (WM), tumble dryers (TD) and dishwashers (DW) in accordance to the statistical data. In order to obtain a high accuracy result, the power consumption of the microgrid model utilises real historical high-resolution data of household energy consumption and RES generation. Thereafter, $40 \%$ of distributed wind and solar energy are implemented in the model to produce two individual scenarios. The operation of the white appliances in the model is controlled using a domestic DSM based on a load shifting algorithm. The primary criterion of the DSM considered in this paper is the reduction of energy feedback to the grid in order to decrease the utilisation of the grid and to reduce the transmission losses. The results obtained from the model simulation are compared to the baseline model and discussed with respect to the possible benefits of implementation of domestic DSM under the impact of RES. It has been shown that the self-consumption ratio of the microgrid operating under the DSM is increased by $3 \%$ for both scenarios. The model analysis provides highly realistic results which can be used for efficiency assessment of various load shifting methods.
\end{abstract}

Keywords: Microgrid; Renewable energy; Demand side management; Load shifting 


\section{Introduction}

The principle of domestic demand-side management (DSM) was introduced firstly in the 80s; however, feasible concepts had not been proposed at these times [1-3]. Subsequently, in the early 90s the developments in internet communication, sensors and actuation technology have provided the technical feasibility of DSM implementation in domestic and commercial sectors [4-6]. In recent years, incoming smart grid technologies and distributed generation using renewable sources have dramatically extended the interest in DSM techniques for energy consumption control in residential areas. DSM becomes an essential component of domestic power systems utilising smart home concepts. It is predicted that domestic DSM will play a significant role in optimisation and efficiency improvement of energy consumption in future residential houses which integrate various controllable loads, renewable and conventional power sources, energy storages etc. [7-9]

\subsection{Domestic Demand Side Management}

The energy consumption control following the DSM approach helps to reduce the energy cost and to improve the efficiency and reliability of the supply network operation. DSM focuses on a customer load profile adjustment to provide energy consumption in an optimal way. It utilises the load management techniques aimed to manipulate load profile curves by several ways: (1) peak clipping; (2) valley filling; (3) load shifting; (4) strategic conservation; (5) strategic load growth; (6) flexible load shape [10]. Although these load manipulation strategies were defined a few decades ago, the resent literature search [11-15] shows that they are still dominating in state-of-the-art DSM proposals and applications in both industrial and domestic sectors. The appropriate DSM technique from the list must be selected with respect to particular system parameters to ensure the most efficient operation of power supply sources. The key system parameter affecting the selection of the strategy is the reliability of forecast/prediction of consumer load profile over a certain period of time. For example, industrial consumers operating in a predictable manner and having a calculable load profile traditionally use a peak clipping DSM strategy to reduce the capacity chargers [16]. In contrast to industrial customers, the power consumption in the domestic sector fluctuates and depends on a large number of factors such as the number and behaviour of household inhabitants, number and type of white good appliances, cost of electricity and gas etc. In addition, if a household is equipped with renewable energy sources (RES) generating electricity with sporadic weather conditions, the prediction of a household energy balance is more sophisticated.

The DSM strategy selection also depends on the structure and controllability of the electrical loads. There is a variety of algorithm approaches implemented into the load control systems to provide DSM operation. It has been admitted that the complexity of the DSM algorithms mainly depends on controllability properties of the electrical load components, electricity metering infrastructure and data communication [17-22]. While industrial consumers utilise comprehensive DSM methods to manage complicate structure load, the domestic DSM systems are relatively simple. Many recent papers [23-25] reported that due to limited control capability of household appliances, the most popular methods for domestic DSM is the load shifting (LS) applied to installed white goods in the form of 'on-off' control.

Volt et al. [26] suggested that most suitable household loads for shifting control under domestic DSM are white goods devices, especially washing machines (WM), tumble dryers (TD) and dishwashers (DW). These appliances can be held and started at a particular time with a time delay. However, there are other household appliances such as freezers or boilers, which could be potentially used for domestic DSM, but their scheduling controllability is extremely limited. Lighting or TVs are considered as non-controllable appliances and, therefore, not objects for the domestic DSM [27]. Many previously published works [23, 28-34] discussed that the LS management of the controllable appliances could be achieved by: (1) direct control using, for example, automation technology for smart homes or (2) indirect control using the participation of household inhabitants in domestic DSM through, for example, financial rewards.

\subsection{Domestic DSM Frameworks and Algorithms}

As discussed above the dominating DSM strategy proposed for the existing housing sector is the load shifting. The frameworks of the domestic DSM utilising LS strategy include the following methods (1) centralised control, (2) distributed control and (3) individual (autonomous) control [35]. Centralised framework provides LS control of a large number of households by a central node or hierarchy management system. The distribution control is usually applied to a smaller number of houses and based on a network which ensures intercommunication between system agents required for decision development. A single household can operate 
under individual (autonomous) control framework. However, the individual control system could be part of centralised or distributed controller.

The load shifting algorithms designed or suggested for domestic DSM applications are usually single or multiobjective optimisation algorithms focusing on optimisation on one or several parameters. In terms of mathematical execution, the LS algorithms operate under various optimisation techniques require, in some cases, significant computational resources.

For example, Abdelsalam et al. [15] suggested a multi-agent optimisation algorithm (antlion algorithm) to analyse three domestic DSM scenarios. Two scenarios represented singe objective optimisation where the objective function is (1) to minimise the energy consumption cost and (2) maximise the load factor. The third scenario is a multi-objective optimisation combining the objective functions from the first and second scenarios. Ebrahimi et al. [14] discussed an advanced particle swarm optimisation algorithm for load shifting control of domestic appliances. Almehizia et al. [36] implemented a genetic algorithm technique to optimise the cost function indirectly reflecting electricity cost. Mehta $e t$ al. [37] proposed an evolutionary optimisation algorithm focusing on keeping the overall load demand below a certain power consumption limit. Jamil and Mittal [13] offered a grasshopper optimisation algorithm to minimise load consumption using LS approach. Analysing LS in a residential area, they assume that the major controllable home appliances include dryer, dishwasher and washing machine.

There is also a number of studies which propose various multi-objectives optimisation algorithms for the domestic LS. For example, Tsagarakis et al. [9] suggested a multi-objective optimisation algorithm to provide LS during the day. The algorithm aimed to optimise the load shifting using two objectives to reduce (1) electricity cost and (2) greenhouse emission. Another multi-objective optimisation algorithm proposed by Ran and Leng [12] focuses on the reduction of electricity cost taking into account the uncertainty of customer behaviour in the form of the robust index (RI).

\subsection{Impact of Renewable Energy Sources}

The role of large- and small-scale RESs in electricity generation is significantly increased over the last decades. Today, small size solar panels and wind turbines are very popular installations improving the energy balance of households. The integration of distributed RES into residential buildings affects the energy consumption profile of domestic households and makes the energy balance analysis more complicate [27]. It is related to the stochastic character of the power generated by RES following the weather conditions. However, the implementation of RES into the residential sector brings new objectives for LS control algorithms. For example, distributed RES can cause energy feedback into the grid; therefore, optimisation focusing the self-consumption would be more efficient in terms of economic benefit as it reduces grid utilisation. The efficiency of LS can also be improved if the forecasting of both the power consumption and the production of the distributed RES are included in LS control. The appropriate forecast suitable for LS could be developed using advanced and thorough analysis of both historical weather and domestic consumption data $[38,39]$.

\subsection{High-Resolution Modelling}

The manipulation of the consumption profile of domestic households in order to synchronise it with the production of domestic RES is a field of intensive research in recent years [40-42]. For example, Javaid et al. [43] deal with the problem of the disparity of domestic consumption and RES production using historical highresolution energy consumption and RES production data in order to develop an effective approach to load shifting. In that paper, the daily and seasonal pattern of the domestic RES is investigated for establishing a schedule which is then used to the load shift. However, this approach is based on empirical values of the past and does not consider short-term effects. Nevertheless, this procedure increases the optimal self-consumed component of the produced RES. Stavrakas and Flamos [21] suggested a high-resolution demand-side management model for a household which can be enlarged in a microgrid comprising a number of buildings. The model is comprehensive and includes solar RES and energy storage. However, the behaviour of the model components is simulated, excluding the weather condition, which utilises historical data. Thiaux et al. [20] introduced a model to investigate the demand-side management in a microgrid (20 households) equipped with solar RES, battery storage and diesel generator. This model runs simulations at a 10-minute time step and also uses historical data of the weather condition. However, the model is designed to analyse a stand-alone microgrid model only. 


\subsection{Contribution}

The present study is focused on the high accuracy assessment of a load shifting method for domestic DSM in the context of RES installed in domestic households. The main contribution of the paper is the development of a microgrid model reflecting RES integration into household power systems and its analysis using an LS algorithm for domestic DSM based on real historical high-resolution data of household energy consumption and RES generation. In contrast to the published works related to high-resolution modelling of domestic power systems, the proposed model implements high accuracy real data of both home appliances' performance and whether condition recorded for the same time period. Implementation of these real data into the investigation model provides highly realistic results which is used for assessment of efficiency of an LS method. As discussed, LS method is recognised as a conventional, simple, effective and probably the only available approach for domestic DSM due to a limited number of controllable appliances and their 'on-off' elementary control nature. In this paper, three types of white goods are taken into account for modelling and analysis of a household energy consumption. These are washing machines, dryers and dishwashers. Small scale and, therefore, distributed RES are studied with respect to their interaction with domestic electricity consumption. The impact of domestic LS is then investigated using a microgrid model. The model of the microgrid for this analysis comprises of 15 households and based on high-resolution historical consumption data provided by the Customer Led-Network-Revolution (CLNR). The data used for the modelling represent the years 2013-2014, and this data is also presumed to be relevant for the near to medium-term future for the vast majority of the households in the UK.

In order to verify the proposed model, the performance of the microgrid is analysed under a case study dealing with a proportion of $40 \%$ distributed RES with respect to the overall consumption of the microgrid. In this investigation, the distributed RES are solar and wind energy sources investigated in two separate scenarios. Both scenarios are developed to provide a thorough assessment of an LS based domestic demand-side management algorithm. The LS management algorithm implemented in the case study is a conventional algorithm based on the criteria of the energy balance of the microgrid. This algorithm is aimed to improve the energy selfconsumption in order to decrease utilisation of the power network and energy losses. It is assumed that the algorithm provides automatic control of the household appliances available for DSM using, for example, smart home actuator technology. However, the algorithm override option is always possible for the household customer to cancel DSM in order to switch to the manual control of the appliances. Finally, the impact of domestic LS implementation is investigated, whereby quantitative as well as qualitative results have been obtained.

\section{Domestic Microgrid Model}

\subsection{Modelling Methodology}

The microgrid model is the main tool for investigation of the RES impact on the energy consumption of the households operating under an LS algorithm. The proposed model operation is based on the principle of energy balance between electricity generation and load consumption. The model consists of a number of households $(m)$ and is supplied from two sources: (1) the grid and (2) renewable energy source (solar or wind).

$$
E_{G R I D}+E_{R E S}=\sum_{k=1}^{m}\left(E_{B A S E(k)}+E_{L S(k)}\right)
$$

where $E_{G R I D}$ is the energy drawn from the grid; $E_{R E S}$ is the energy produced by renewable energy sources; $E_{B A S E(k)}$ is the energy consumed by uncontrolled (base) loads of $k$-th household; $E_{L S(k)}$ is the energy consumes by shiftable household appliances in $k$-th household; $m$ is the number of households in the residential microgrid model.

It is assumed that the model included three types of controllable (available for load shifting) appliances: washing machine; tumble dryers and dishwasher. The energy consumed by these appliances in $k$-th household $E_{L S}$ is represented as follows

$$
E_{L S(k)}=d_{k, 1} E_{W M}+d_{k, 2} E_{T D}+d_{k, 3} E_{D W}
$$


where $d_{k, 1}$ is model dissemination coefficient of the washing machines; $d_{k, 2}$ is model dissemination coefficient of the tumble dryers; $d_{k, 3}$ is model dissemination coefficient of the dishwashers; $E_{W M}$ is the energy consumed by washing machine; $E_{T D}$ is the energy consumed by tumbler dryer; $E_{D W}$ is the energy consumed by dishwasher. The model dissemination coefficients specify the distribution of controllable appliances across the model households. The coefficient is 1 if the $k$-th household is equipped with an appropriate appliance; it is 0 if the appliance is not installed.

Therefore, the energy consumption by shiftable loads of the model households can be represented as column matrix $\mathbf{E S L}[m]$ having $m$ elements in the row.

$$
\mathbf{E}_{\mathrm{LS}}=\mathbf{D} \cdot \mathbf{E}
$$

where $\mathbf{D}[m, 3]$ is a binary matrix of the model dissimilation coefficients. The matrix consists of three columns corresponding to three types of shiftable appliances and $m$ rows corresponding to the number of households in the model.

$$
\mathbf{D}=\left[\begin{array}{ccc}
d_{1,1} & d_{1,2} & d_{1,3} \\
d_{2,1} & d_{2,2} & d_{2,3} \\
\ldots & \ldots & \ldots \\
d_{m, 1} & d_{m, 2} & d_{m, 3}
\end{array}\right]
$$

$\mathbf{E}[3]$ is the column matrix of the energies consumed by three shiftable appliances. Hence, the matrix has three elements in one column.

$$
\mathbf{E}=\left[\begin{array}{c}
E_{W M} \\
E_{T D} \\
E_{D W}
\end{array}\right]
$$

The energy consumed by controllable appliances over simulation time span consisting of $n$ time samples are represented below. The activation coefficient $g$ at $i$-th time sample in (6)-(8) is $g=1$ if an appliance is in operation and $g=0$ if the appliances is on hold.

$$
\begin{aligned}
& E_{W M}=\sum_{i=1}^{n}\left(P_{W M} g_{i} h\right) \\
& E_{T D}=\sum_{i=1}^{n}\left(P_{T D} g_{i} h\right) \\
& E_{D W}=\sum_{i=1}^{n}\left(P_{D W} g_{i} h\right)
\end{aligned}
$$

where $P_{W M}$ is rated power of WM; $P_{T D}$ is rated power of TD; $P_{D W}$ is rated power of DW; $h$ is the time sample rate.

\subsection{Domestic Load Profile Assembly}

The core of the domestic microgrid model consists of 15 households $(m=15)$ performing differently in terms of energy consumption. The load profiles of the households combined into a microgrid are summarised in order to deliver a sophisticated picture of the total microgrid energy balance. This investigation uses historical electricity consumption data of domestic households from the CLNR. The CLNR is the most profound investigation regarding the monitoring of domestic energy consumption. Data of approximately 13,000 households have been collected by the CLNR between the year 2012 and 2014. The results of the CLNR are provided in several databases with different monitoring approaches. 


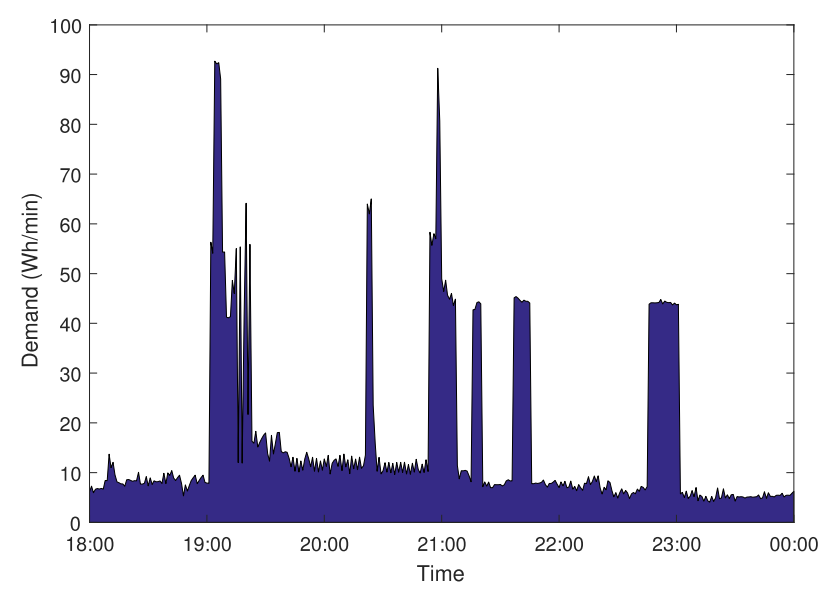

Fig. 1. An example of the energy demand of one household over 6 hours from 18.00 to 24.00 .
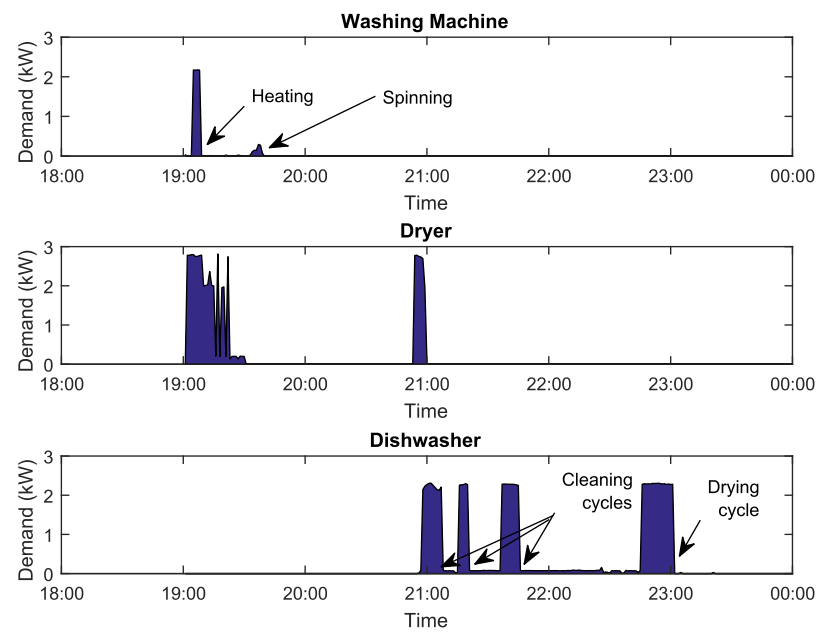

Fig. 2. An example of the energy demand of the individual appliances of the household.

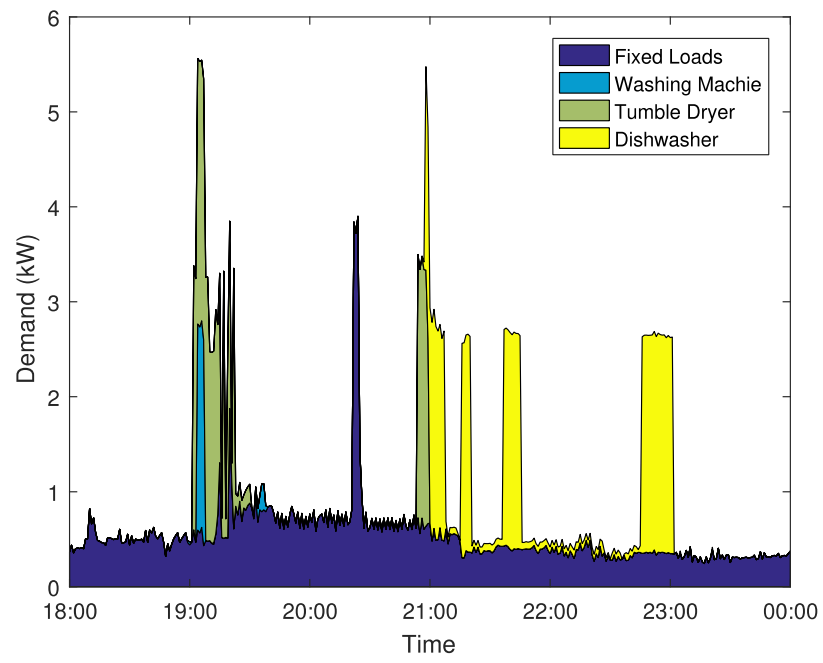

Fig. 3. The assembled energy demand profile of the household showing the demands by the shiftable appliances (washing machine, tumble dryer, dishwasher) and the appliances not available for the load shifting (fixed load).

The first used database is the 'TrialMonitoringDataMicrowatt' which contains the overall consumption of a household [44]. The sample rate of the used data is 1 minute, whereby the used unit for the demand is $\mathrm{Wh} / \mathrm{min}$ 
because the used meters integrated the consumption for the obtained samples. Fig. 1 shows an example of the energy demand of one household extracted from the database. The example demonstrates the energy consumption over 6 hours in the evening - from 18.00 to 24.00. It can be seen that this profile has a certain basic load and some peaks related to the operation of the white goods appliances. It is assumed that the basic load is non-controllable demand, whereas peak loads belong to the appliances available for the LS control (shiftable household appliances).

In order to determine the energy consumption by individual loads within a household power system, the 'TrialMonitoringDataPassiv' database has been utilised for the data processing. This database also has a sample rate of 1 minute; however, in contrast to the previous database, its unit is $\mathrm{kW}$ because the demand has been measured punctual The data extracted from the database are used to determine the demand caused by the shiftable appliances. Fig. 2 shows an example of the energy demands produced by three shiftable appliances of one household: washing machine, dryer, and dishwasher.

Finally, the data of both databases are assembled into the form of the energy demand profile (Fig. 3), which takes into account the consumption of the shiftable appliances. This type of energy demand profile is the foundation for further modelling procedures.

\subsection{Model Architecture}

15 UK households proposed for the microgrid model are located somewhere inside the Northern Powergrid, one of 14 distribution network operators across the UK, covering areas of North East of England, Yorkshire and North Lincolnshire. The exact locations of the household are not provided by the CLNR in order to protect the privacy of the residents. The first aspect considered regarding the microgrid model is the dissemination of the shiftable domestic appliances in the UK. Hence, the UK's dissemination of WM, TD and DW is presented in Table 1.

Table 1. The dissemination of the domestic appliances of the microgrid [45-47].

\begin{tabular}{|l|l|l|}
\hline Appliances & Dissemination (UK) & Dissemination (Microgrid model) \\
\hline Washing Machine & $97 \%$ & $100 \%(15 / 15)$ \\
\hline Tumble Dryer & $56 \%$ & $53.33 \%(8 / 15)$ \\
\hline Dishwasher & $45 \%$ & $45.67 \%(7 / 15)$ \\
\hline
\end{tabular}

Table 2. The weeks for the different seasons considered for the microgrid analysis

\begin{tabular}{|l|l|l|l|}
\hline Season & Start Date & End Date & Days \\
\hline Spring & 17.03 .2014 & 23.03 .2014 & 7 \\
\hline Summer & 17.06 .2013 & 23.06 .2013 & 7 \\
\hline Autumn & 16.09 .2013 & 22.09 .2013 & 7 \\
\hline Winter & 16.12 .2013 & 22.12 .2013 & 7 \\
\hline
\end{tabular}

In order to establish a profound microgrid model, the season variations in the energy consumption have to be considered. Hence, there is the need to define the time-spans for the respective seasons of the year. The selected time-spans are representing 7 days in each season (Table 2). Subsequently, consumption profiles have been selected in order to match the before presented dissemination.

In terms of the total microgrid consumption, the individual peaks of the households are smoothed by the other houses in the microgrid model. Therefore, the microgrid model is used to determine a baseline model of household energy consumption. This baseline model of an average household is taken into consideration as a reference for further investigation.

An additional component related to the renewable energy source (RES) is included in the microgrid model. This component represents two RES options: (1) solar panels installed in the households and combined into one source or separate solar microgrid farm and (2) microgrid wind farm. Both RES options are analysed in the case study separately. The microgrid feeder is connected to the main grid through a smart meter which is installed to 
provide the readings of the microgrid energy balance. This balance is then used as the main criteria for the LS algorithm. The schematic structure of the proposed domestic microgrid is shown in Fig. 4.

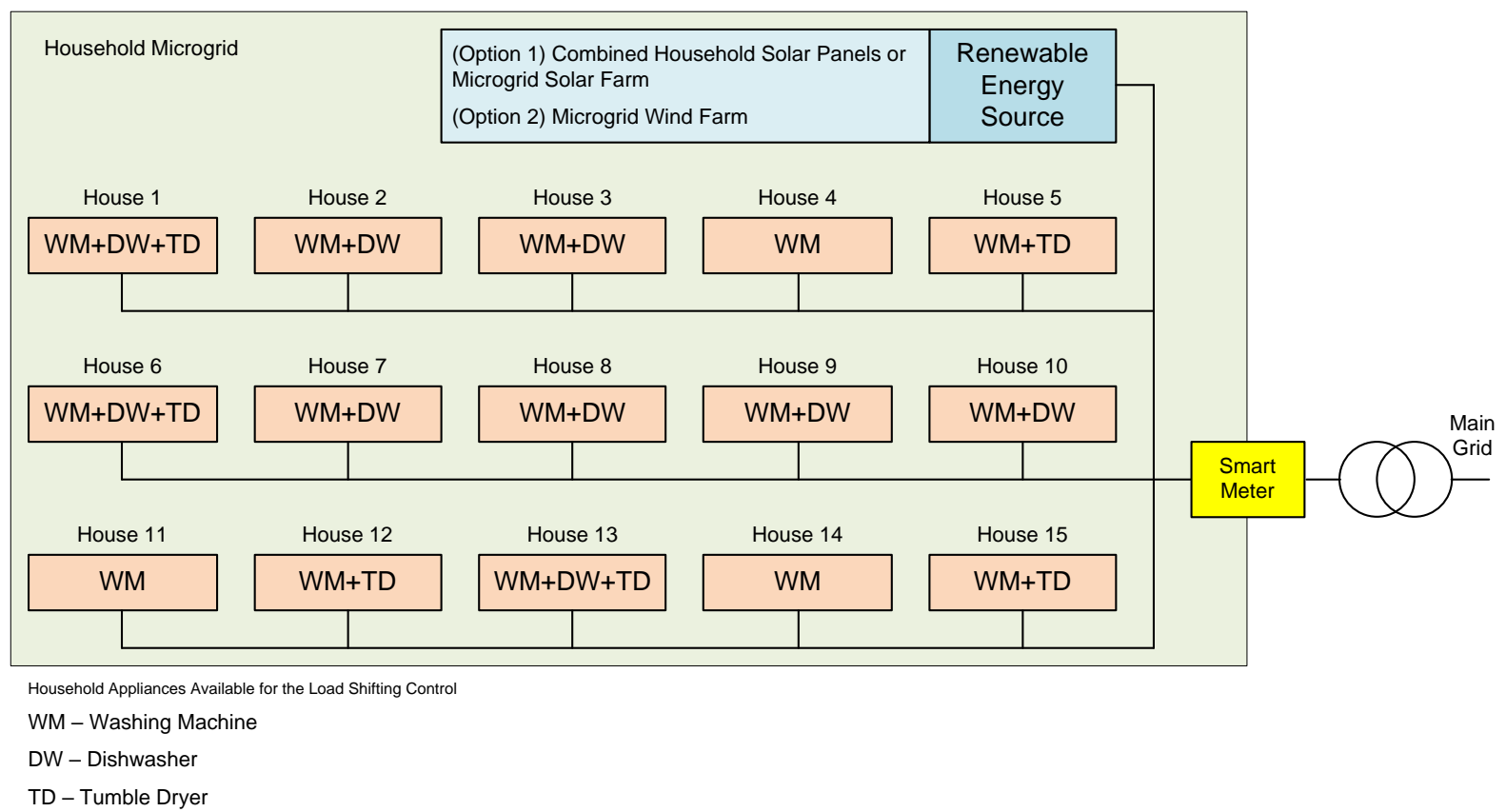

Fig. 4. The structure of the microgrid model.

\section{Baseline Model}

The baseline model represents an energy consumption of an average household developed from the combination of the energy demands of 15 households allocated in the microgrid model. The results obtained from the baseline simulation are used as a reference for further energy demand management measures. The load management algorithm described and assessed in the case study is actually based on the consumption behaviour of the baseline model. The baseline model results have to be compared with statistical data in order to provide the microgrid model validation.

\subsection{Daily Domestic Load Profile}

In order to demonstrate the expected benefits of domestic load shifting regarding the daily domestic load profile, it is necessary to get knowledge about the initial situation. Fig. 5 shows the results obtained from the analysis of the initial system without any load shifting measures. It can be seen that the daily energy demand profile demonstrates the morning demand surge and the overall demand peak during the evening. In addition, there is a lower energy demand during the worktime occupation gap (9:00-16:00). Analysis of the load profile of the shiftable loads determines that there are two peaks - the first peak is in the morning from 8:00 to 12:00 and the second one in the afternoon from 17:00 to 21:00. The demand drop in the late evening is caused by the residents who went to bed and, therefore, stopped consuming energy. 

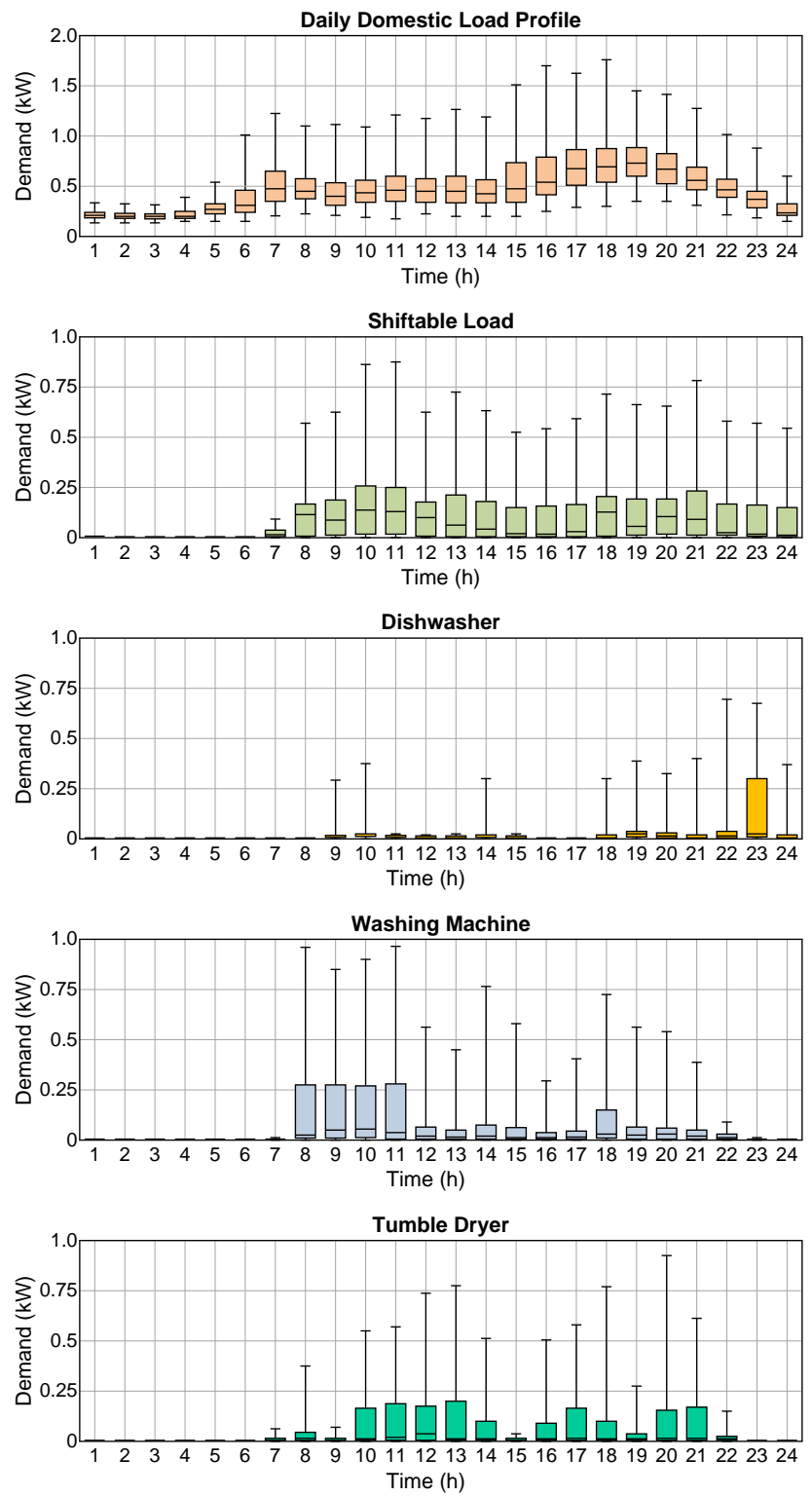

Fig. 5. Daily energy demand profile of one average household of the microgrid.

\subsection{Weekly Domestic Load Profile}

Fig. 6 shows the weekly load profile combined with the shiftable load to demonstrate the opportunities for the domestic load shifting. The profile is based on a 6-minute sample rate to make the graph surface smoother. It can be seen that the energy demand is similar on weekdays. In contrast to the weekdays, the weekend has a significantly different consumption profile where more shiftable appliances are in operation causing the weekly routines of the residents. 

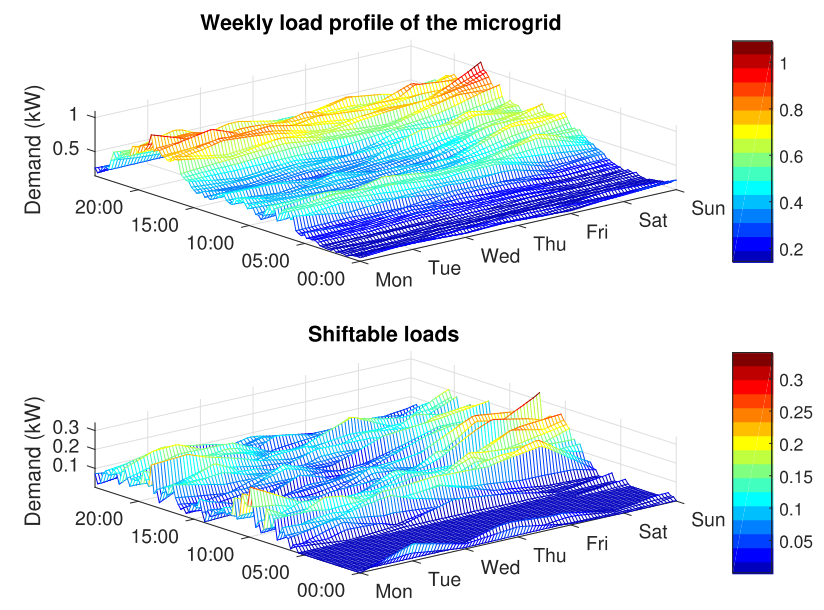

Fig. 6. Weekly average energy demand of one household of the microgrid.

\subsection{Daily Load Profile with Respect to the Season}

The domestic energy consumption is strongly linked to the seasons; consequently, the seasonal impact needs to be considered by the model. Analysis of the domestic energy demand with respect to the season shows that the highest energy demand occurs during the winter; in contrast, the summer is the season with the lowest energy demand. The energy demand during spring and autumn are similar. The average demand for one household is shown in Fig. 7.
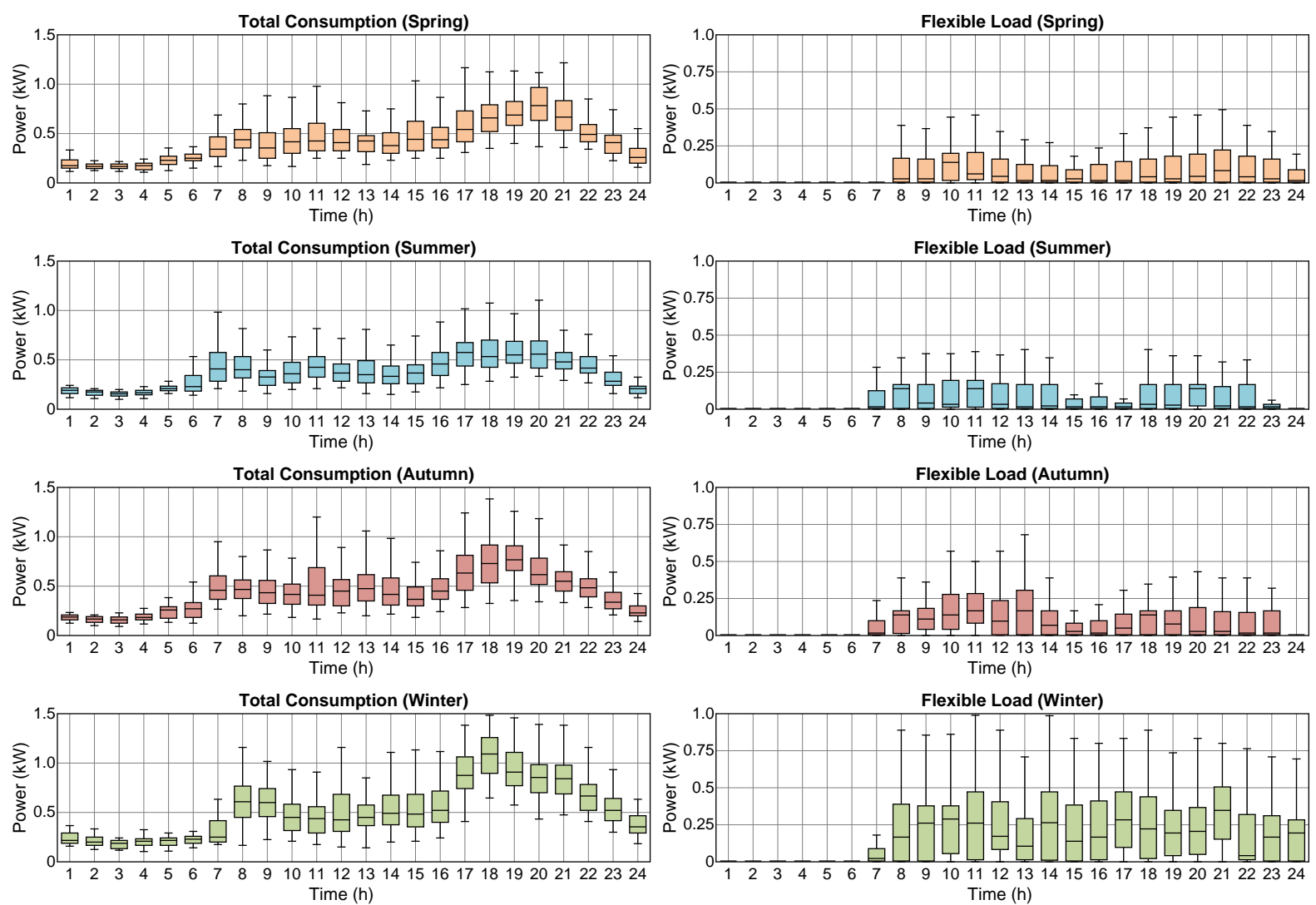

Fig. 7. Energy demand of one household with respect to the season.

To ensure understanding of the daily consumption variation of the single house, there is a need for a histogram demonstrating the distribution of energy consumption. Hence, individual values of the houses are required instead of average values which have been used for the graphs before. When considering the consumption behaviour shown in Fig. 8 it can be determined that more than $90 \%$ of the consumption is between 0 and $1 \mathrm{~kW}$. 
Moreover, the histogram shows a higher probability of consumption above $1 \mathrm{~kW}$ during the winter in comparison to the spring, summer and autumn scenario. It can also be recognised that the summer scenario has the highest probability of consumption below $0.5 \mathrm{~kW}$.
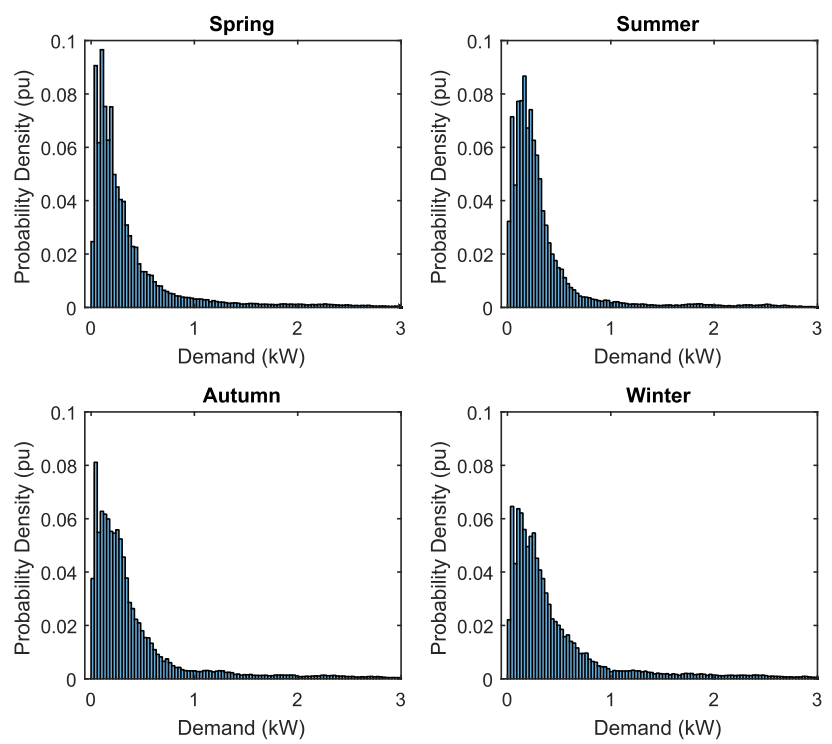

Fig. 8. The consumption distribution of the single houses used for the microgrid model.

\subsection{Validation of the Baseline Model}

In order to use the baseline model for further load shifting measures, there is a need to prove the plausibility. Therefore, the baseline model is compared with official data of UK households regarding the overall electricity consumption and the daily load profile. The data provided by the CLNR have been collected between 2013 and 2014; hence, statistics of the year 2014 are considered for the validation of the baseline model.

Overall electricity consumption: When considering the data provided by the Department of Climate \& Energy Change, the average annual electricity consumption of a UK household is $4001 \mathrm{kWh}$ [48]. The annual electricity consumption of the baseline model is $3885 \mathrm{kWh}$; consequently, it can be said that the overall consumption of the microgrid is plausible.

Daily load profile: The diurnal domestic load profile has two peaks, the first in the morning when the residents get ready for the day and the second when the residents come back home. Moreover, there is a large consumption 'valley' during the night and a less significant 'valley' from 10:00 to 16:00 caused by lower residential occupation regarding this time span. The described daily demand characteristic of the baseline model concurs with the data provided by [49].

Difference between working and weekend days: In contrast to the weekdays, the weekend days have a less clear pattern regarding the diurnal peaks. The daily routines during the weekend vary much more; therefore, the consumption pattern is quite different with respect to working days. The results of the baseline model regarding the workday/weekend day deviation are very similar to the results provided by Richardson et al. [50] where the authors investigated the consumption differences between working days and weekends days.

Therefore, it has been confirmed that the baseline model results are in accordance with the results of other researchers and official institutions regarding the total electricity consumption and its variation characters. Consequently, the baseline model can be used for further load shifting measures in order to demonstrate the impact of domestic energy usage on a future Smart Grid.

\section{Case Study}

The developed microgrid model is used as an analytical tool for the investigation of the LS approach using a case study. The case study represents two options of the RES integration into the microgrid model: a scenario with distributed solar energy and a scenario with distributed wind energy. Both scenarios assume that the rated power of distributed RES integrated into the microgrid model comprises $40 \%$ of the microgrid consumption. 


\subsection{Implementation of Environmental Data}

In order to simulate a microgrid model which considers the impact of fluctuating RES, it is necessary to use historical climate data. Therefore, data provided by the Met Office Integrated Data Archive System (MIDAS) have used to reproduce the impact of distributed RES. This investigation considers environmental data closed to Grimsby in the UK because it is located inside the Northern Powergrid, the only known location identifier provided by the CLNR. The used solar radiation data is provided by the dataset 'MIDAS: Global Radiation Observations', whereby the sample time is 1 hour [51]. The used wind data for this investigation are extracted from the dataset 'MIDAS: UK Mean Wind Data', whereby the sample time is 1 hour [52].

\subsection{Determining the Amount of Distributed RES}

Firstly, there is a need to determine the total energy consumption of the microgrid. The microgrid model considers all seasons with respectively one week and a sample time of 1 minute; thus, there are 40320 samples.

$$
E_{B}=\sum_{i=1}^{40320} e_{B, i}
$$

where $E_{B}$ is the total energy consumption of the microgrid; $e_{B}$ is a 1-minute sample of the microgrid energy consumption.

Next, the gained total energy consumption of the microgrid is used to determine the produced energy by distributed RES.

$$
E_{P V}=E_{W T}=E_{B} \times 0.4
$$

where $E_{P V}$ is total energy produced by solar panels; $E_{W T}$ is total energy produced by wind turbines.

\subsection{Modelling of the Distributed Solar Energy}

State of the art solar panels have currently an efficiency of around 20\% [53]. Hence, when considering the starting solar irradiation of [54,55], the output of the solar panels can be described as follows:

$$
F_{P V}= \begin{cases}0 & \text { if } S I<50 \mathrm{~W} / \mathrm{m}^{2} \\ \left(S I-50 \mathrm{~W} / \mathrm{m}^{2}\right) \times 0.20 & \text { f } S I>50 \mathrm{~W} / \mathrm{m}^{2}\end{cases}
$$

where $F_{P V}$ is the output of the solar panels in $\mathrm{W} / \mathrm{m}^{2} ; S I$ is the solar irradiation in W/m².

The microgrid model considers all seasons with respectively one week and a sample time of 1 hour; thus, there are 672 samples. Hence, the average output of the solar panels is determined by using the following equation.

$$
F_{P V a v g}=\frac{\sum_{i=1}^{672} F_{P V, i}}{672}
$$

where $F_{\text {PVavg }}$ is the average output of the solar panels in $\mathrm{W} / \mathrm{m}^{2}$.

Consequently, the equation for determining the amount of distributed RES can be rewritten as follows.

$$
E_{P V}=F_{P V a v g} \times A_{P V} \times t
$$

where $E_{P V}$ is total energy produced by solar panels; $A_{P V}$ is the area of the solar panels in $\mathrm{m}^{2}$; $t$ is the entire timespan of the simulation.

Thus, the area is calculated as shown below.

$$
A_{P V}=\frac{E_{P V}}{P_{P V a v g} \times t}
$$


The finally calculated area of the solar panels is then used to determine the solar energy samples which will be implemented to the microgrid model. According to (6), the area of the solar panels is $36 \mathrm{~m}^{2}$.

\subsection{Modelling of the Distributed Wind Energy}

When considering [56], the output factor of the wind turbines can be described as follows:

$$
F_{\text {WTin } \%}= \begin{cases}0 & \text { if } 0 \mathrm{~m} / \mathrm{s}<v_{\text {Wind }}<3 \mathrm{~m} / \mathrm{s} \\ \left(v_{\text {Wind }}-3 \mathrm{~m} / \mathrm{s}\right) \times 12.5 \frac{\%}{\mathrm{~m} / \mathrm{s}} & \text { if } 3 \mathrm{~m} / \mathrm{s}<v_{\text {Wind }}<11 \mathrm{~m} / \mathrm{s} \\ 100 \% & \text { if } 11 \mathrm{~m} / \mathrm{s}<v_{\text {Wind }}<20 \mathrm{~m} / \mathrm{s} \\ 0 & \text { if } 20 \mathrm{~m} / \mathrm{s}<v_{\text {Wind }}\end{cases}
$$

where, $F_{W T}$ is the output factor of the wind turbines in $\%$; $v_{\text {Wind }}$ is the wind speed in $\mathrm{m} / \mathrm{s}$.

Next, the average load factor of the wind turbine is determined by the following equation.

$$
F_{\text {WTavg }}=\frac{\sum_{i=1}^{672} F_{W T, i}}{672}
$$

where $F_{\text {WTavg }}$ is the average output factor of the wind turbines.

Hence, the equation for the energy produced by wind turbines can be rewritten as follows.

$$
E_{W T}=F_{W T a v g} \times P_{W T r a t e d} \times t
$$

where $P_{W T r a t e d}$ is the rated power of the wind turbine in $\mathrm{kW}$.

Finally, the rated power of the wind turbine can be calculated as shown below.

$$
P_{\text {WTrated }}=\frac{E_{W T}}{F_{W T a v g} \times t}
$$

The rated power of the wind turbine is then used to determine the wind energy samples which will be implemented to the microgrid model. According to (15), the rated power of the turbine is $4.8 \mathrm{~kW}$.

In order to meet the afore defined proportion of $40 \%$ distributed RES, the following expression has to be true.

$$
E_{W T}=E_{B} \times 0.4=\sum_{i=1}^{672}\left(F_{W T, i} \times P_{W T r a t e d} \times 1 \mathrm{~h}\right)=\sum_{i=1}^{672}\left(F_{P V, i} \times A_{P V} \times 1 \mathrm{~h}\right)
$$

\subsection{Energy Production of the Microgrid}

Based on this approach, the obtained solar energy can be seen in Fig. 9. When analysing the solar energy profile, it can be determined that the spring and the autumn have a similar pattern; however, the summer has the highest energy yield. In contrast, the energy produced in the winter is almost negligible. Moreover, there is a high dayto-day fluctuation for all seasons.

Subsequently, the wind energy has been generated (Fig. 10) based on the previously shown procedure, which uses historical wind data. In contrast to the profile of solar energy, the load factor of wind energy is significantly higher. However, the load profile of wind energy also fluctuates. 

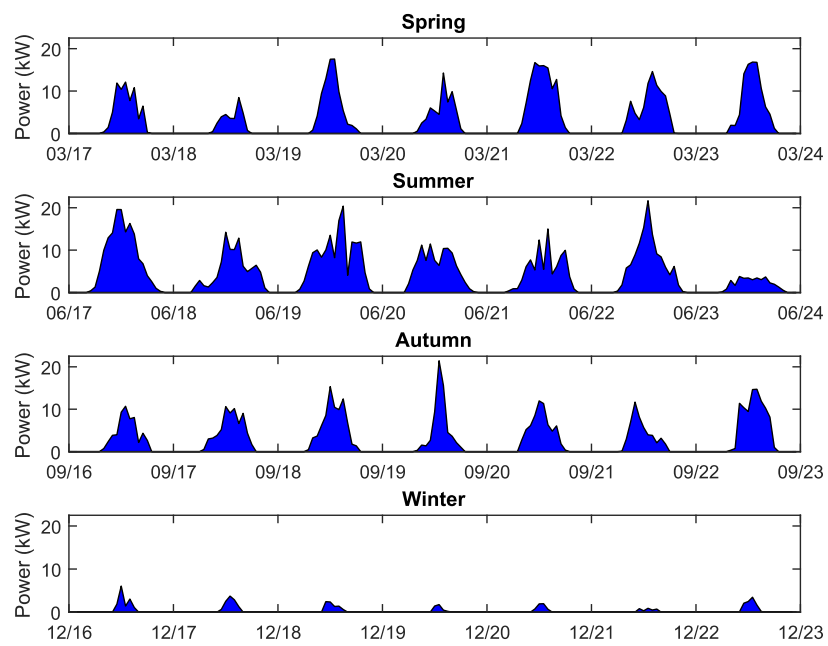

Fig. 9. The distributed solar energy which has been feed-in the microgrid.
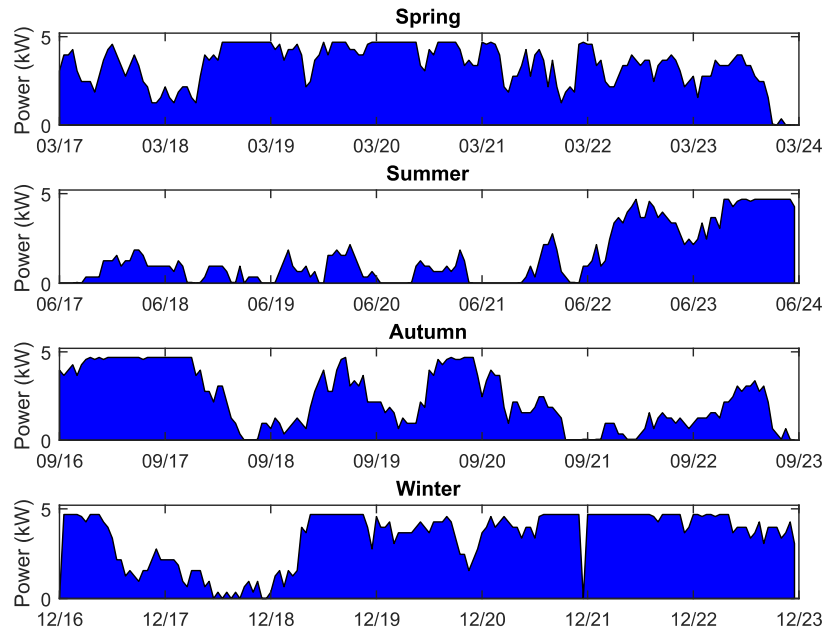

Fig. 10. The distributed wind energy which has been feed-in the microgrid.

\subsection{Energy Balance of the Microgrid with Distributed RES}

When merging the consumption profile and the energy production of the microgrid, the energy transmission between the micro and macro grid results are considered. The resulting energy transmission of the solar energy scenario is, therefore, shown in Fig. 11, whereby the seasons of the year have been considered.

Following, the domestic consumption profile has been merged with the production profile of the wind turbines. The resulting energy transmission profile with respect to the seasons is presented in Fig. 12. In contrast, to the solar energy scenario, there is less energy feedback caused by the high load factor of wind energy. 

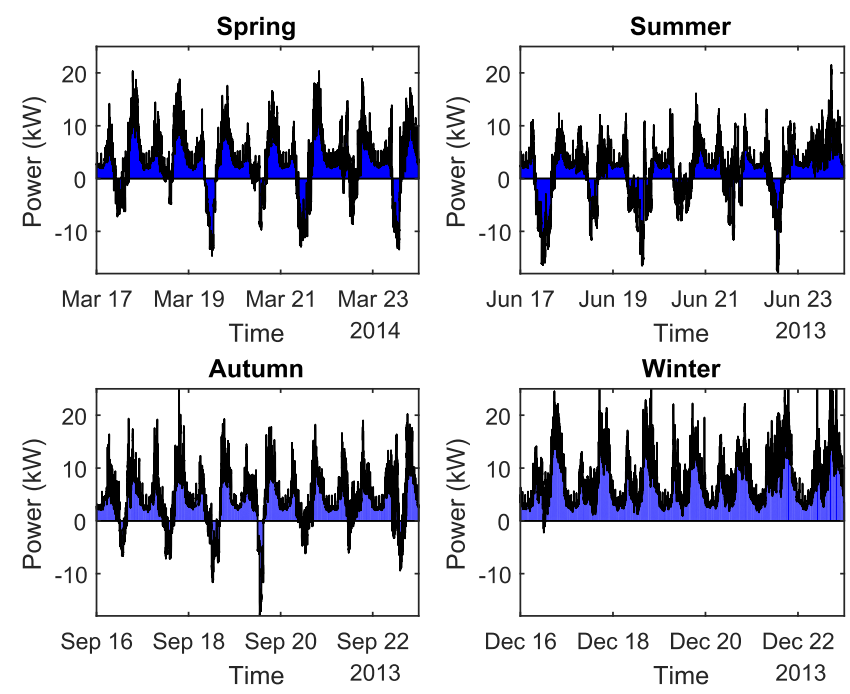

Fig. 11. The energy transmission of the microgrid in the context of solar energy (negative value shows the energy feedback).
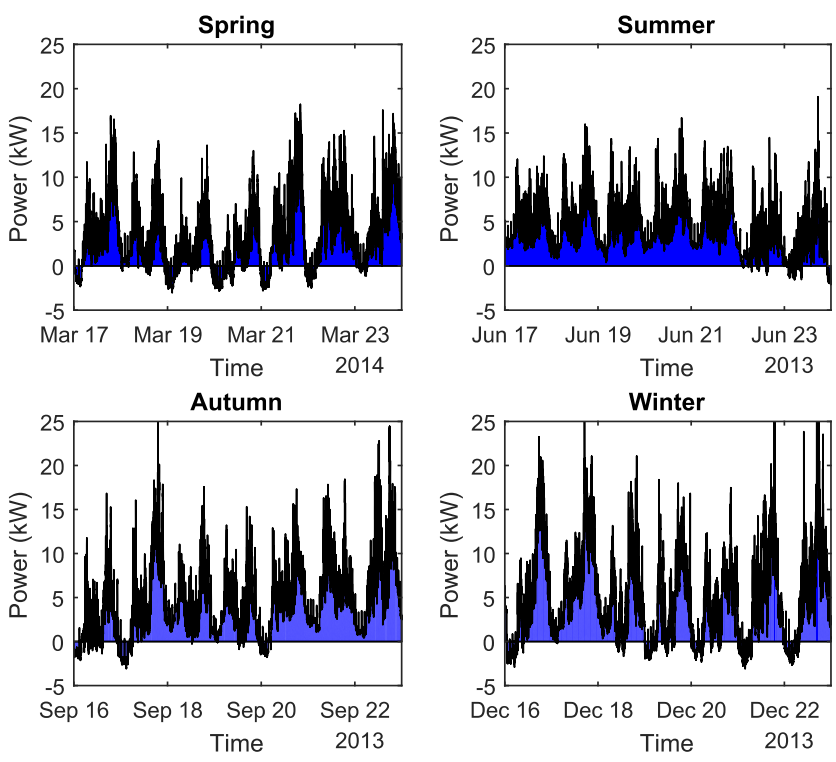

Fig. 12. The energy transmission of the microgrid in the context of wind energy (negative value shows the energy feedback).

Both scenarios of the case study applied to the model demonstrate that the microgrid generates a certain amount of electrical energy transmitted into the main grid. It can be seen that generated electricity is variable and its production mainly depends on the season and weather condition. The results obtained from the case study are based on high-resolution historical data and show a highly realistic picture of the microgrid performance under the impact of RES.

\section{Demand Side Management using Load Shifting}

At the next stage, the model is extended by the load shifting algorithm to provide the DSM operation, where the previously obtained data are used as an input for the investigation of both scenarios of the case study. The flowchart of the implemented LS algorithm is shown in Fig 13.

The applied LS algorithm is a conventional, simple algorithm considered as an example to demonstrate the ability of the model to provide the efficiency assessment. The LS algorithm utilises an elementary 'on-off' control and is based on the microgrid energy balance criteria. It is designed to control three types of white machines: washing machines, tumble dryers and dishwashers. However, the distribution of these appliances across the households varies as shown in Fig. 4. 


\subsection{Load Shifting Criteria for the Algorithm}

Energy Balance: The first criterion which is considered is the energy balance of the microgrid. According to this criterion, the shiftable appliances are only started when the energy balance is negative in order to reduce the energy feedback of the microgrid.

Priority Mode: In case if the consumer wants to operate an appliance manually, there is the possibility to start the appliance with priority mode, which means that the appliance starts unconditionally. This investigation considers the priority mode for the historical consumption data only in the case of operation sequence, because the load shifting of the appliances is then certainly not possible and the priority mode is necessary in any case.

Promising shifting time: In order to determine the promising shifting time, the type of distributed RES has to be considered. Following the interaction of energy demand and energy production, which can be seen in Fig. 11 and Fig. 12, the energy feedback is represented in terms of a daily pattern. Consequently, the load shifting algorithm, which holds the appliances in a waiting loop, only enables before a promising shifting time. Moreover, in the case of solar energy, the season is also considered because the solar energy yield during the winter can be neglect.

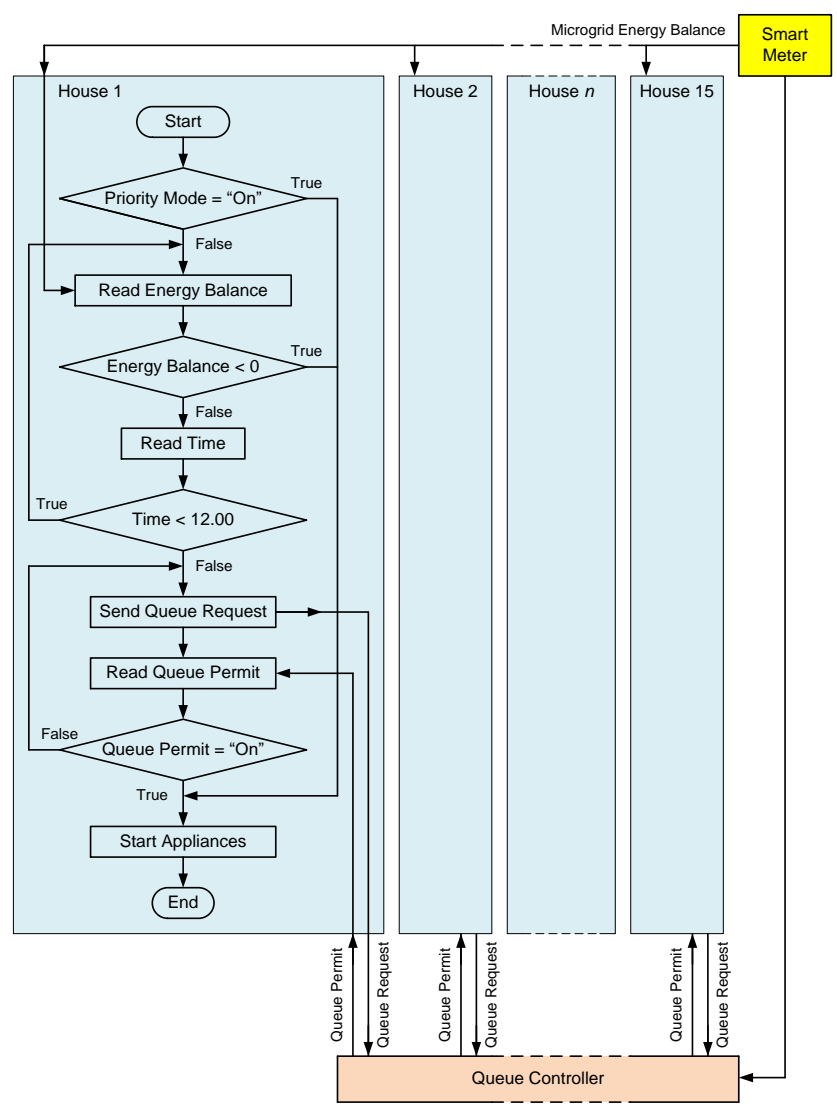

Fig. 13. Flowchart of the load shifting algorithm.

\subsection{The Load Shifting Algorithm}

The LS algorithm shown in Fig. 13 is based on the afore presented criteria. It can be seen that, according to the algorithm, each household of the microgrid operates independently, whereas the smart meter monitors the connection of the microgrid to the feeder and provides the readings of energy balance. These readings are the input variable for each household algorithm sequence. The algorithm is equipped with the queue controller, which is common for all houses in the microgrid model. The purpose of the queue controller is to collect the requests from the households asking to start appliances outside the time interval available for the LS operation. It is assumed that the time where the LS algorithm enables is set from 5:00 to 12:00. Therefore, the queue controller prevents a massive pick of energy demand at 12:00 if all household appliances start simultaneously in an automatic mode. At 12:00 the controller holds all requests in a queue and gives the permissions to start appliances with a certain time delay. The queue controller can be overridden under the priority mode. 


\section{Results and Discussion}

\subsection{Domestic Load Shifting in Context of Solar Energy}

The determination of the promising shifting time is the first step of the solar energy scenario. Therefore, Fig. 5, which shows the daily load profile of the shiftable load, and Fig. 11, which presents the energy balance of microgrid, must be analysed. Firstly, Fig. 11 shows that the energy feedback takes place mostly between morning and early afternoon; however, particularly at noon. Therefore, the LS algorithm must be enabled between the early morning and the noon, where the LS algorithm keeps the shiftable loads in the waiting loop until the energy balance is negative. Thus, the time when the LS algorithm enables is set from 5:00 to 12:00. In the case of a cloudy day, all appliances, which are in the waiting loop, will start at 12:00 in any case. The resulting LS measures are then presented in Fig. 14.
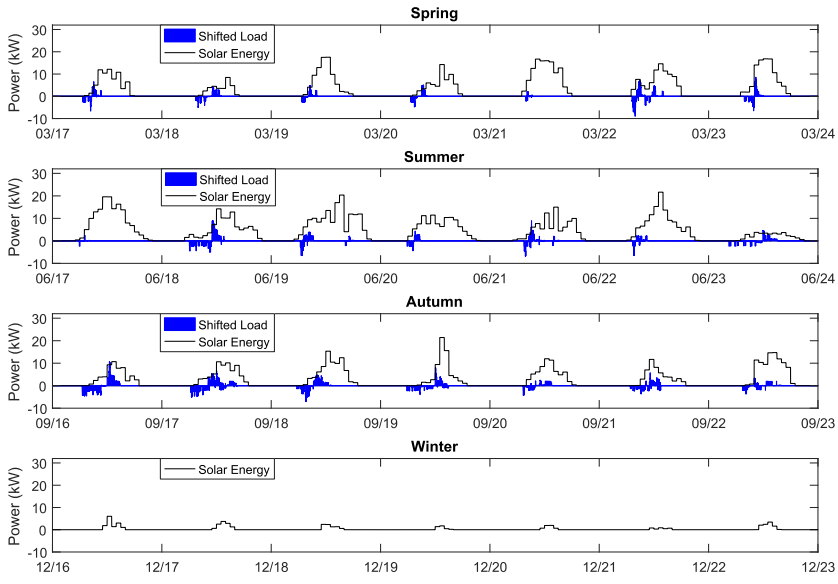

Fig. 14. The load shifting measures in relation to the produced solar energy.
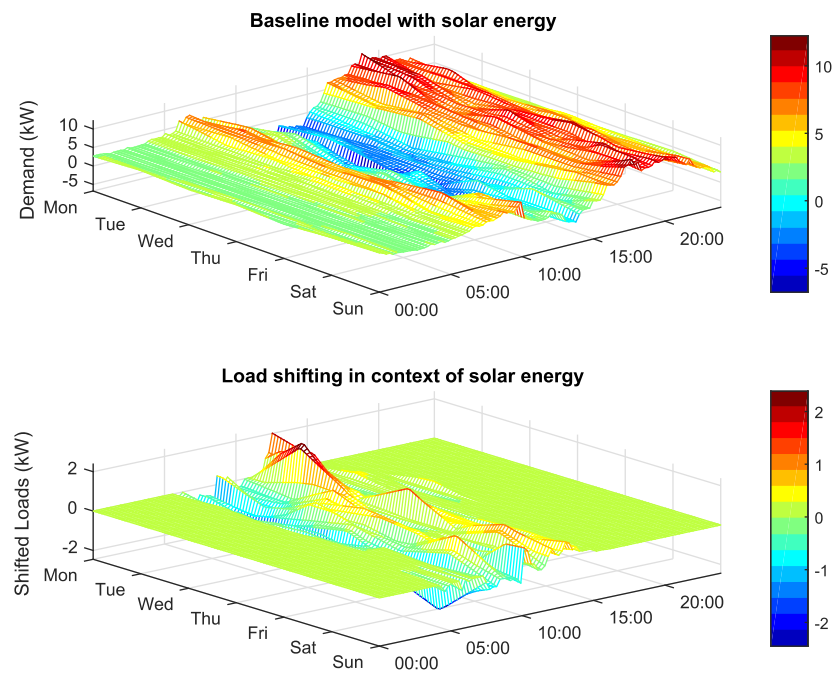

Fig. 15. The energy balance in relation to the shifted energy in the context of solar energy.

Next, the LS is compared with respect to the energy balance profile of the microgrid. It can be recognised that the shiftable loads are shifted in accordance with the algorithm presented in Fig. 13 with the aim of building a load during noontime. Moreover, the load shifting in the context of solar energy reduces the domestic energy demand during the morning, when the residents are getting ready for leaving the house. The comparison of the domestic energy balance and shifted loads in the context of solar energy are presented in Fig. 15.

Subsequently, the probability of the energy balance is analysed regarding the impact of domestic LS, whereby the seasons of the year have been considered. This comparison, shown in Fig. 16, demonstrates a decreased probability of energy feedback and high energy consumption; additionally, an increase in the probability regarding low energy consumption has been pointed out. When considering the season, it can be recognised that 
there is no LS measured during the winter and the impact of domestic load shifting in the context of solar energy is highest during the transition periods spring and autumn.
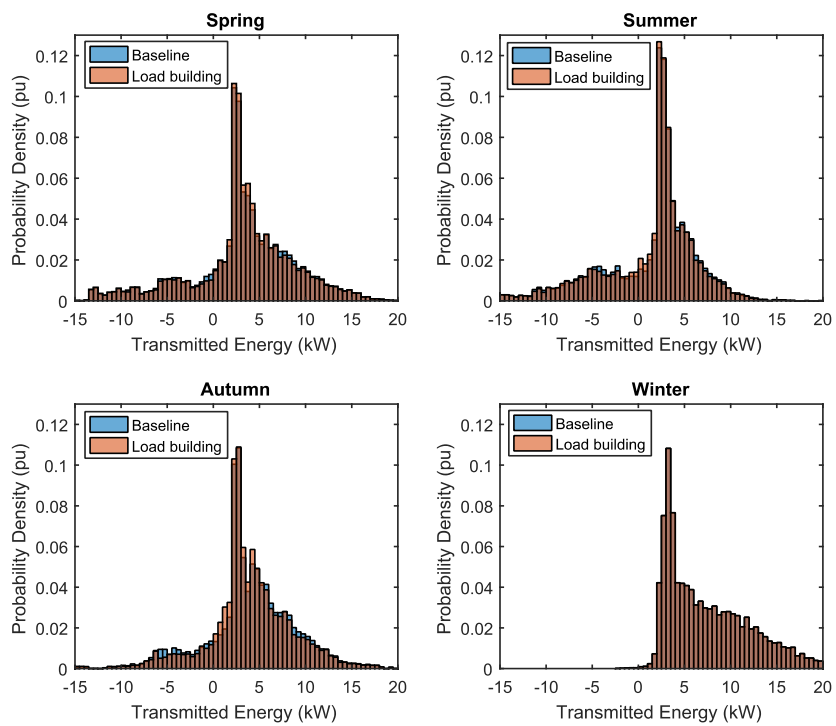

Fig. 16. Comparison of the energy balance of the microgrid regarding domestic load shifting.

\subsection{Domestic Load Shifting in Context of Wind Energy}

At the next step, this study investigates the domestic LS in the context of wind energy. In accordance with the wind energy scenario, the first action is the determination of the promising shifting time. When considering the daily characteristic of the shiftable loads presented in Fig. 5 and the energy feedback characteristic demonstrated in Fig. 12, it can be seen that the evening peak of the shiftable loads can be used to reduce the energy feedback during the night. Hence, the domestic LS is enabled from 16:00, caused by the end of the intraday occupation gap, and ends at 00:00. The resulting shifted loads are presented in Fig. 17 with respect to the wind energy yield.
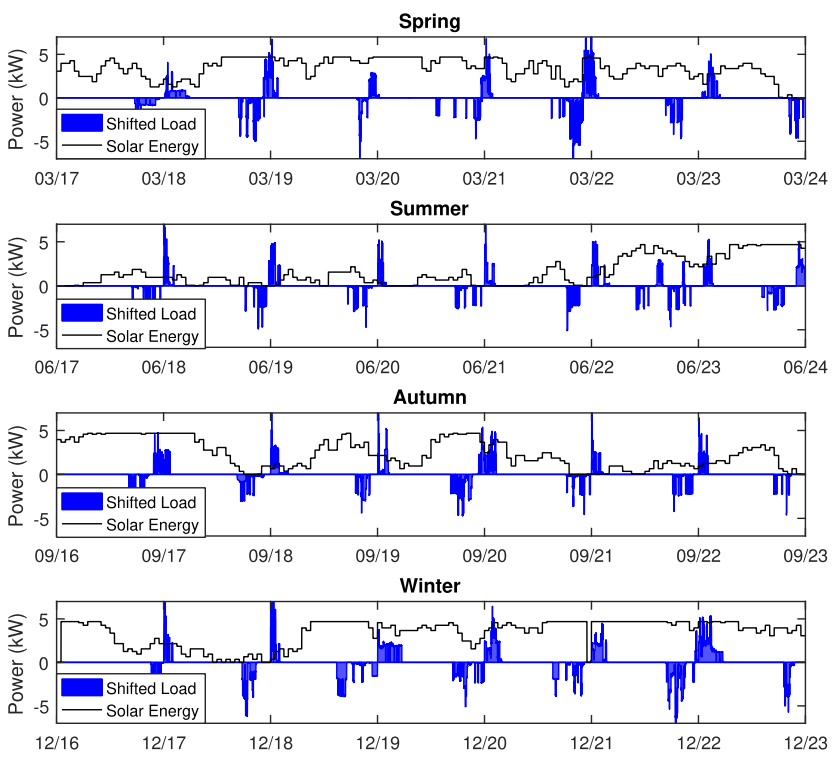

Fig. 17. The load shifting measures in relation to produced wind energy. 

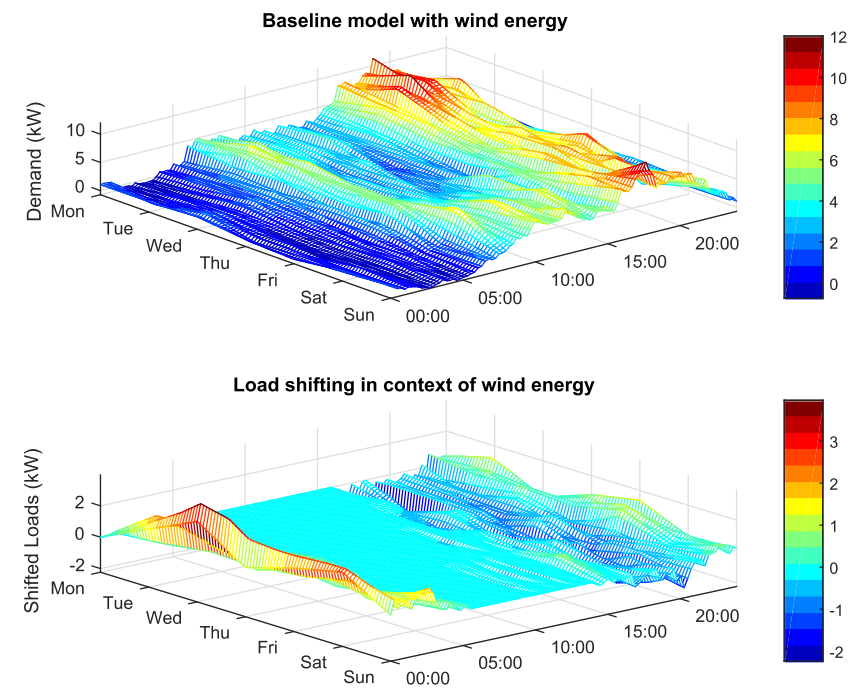

Fig. 18. The load shifting measures in relation to the energy balance in the context of wind energy.

Next, the shifted loads are analysed with respect to the weekly energy balance, where an average season model has been used. In contrast to the solar energy scenario, a load has been built during the late evening and early night. Moreover, the LS in the context of wind energy reduces the energy demand during the peak time in the evening. The comparison of the domestic energy balance and shifted loads in the context of wind energy are presented in Fig. 18.

Finally, the probability of the energy balance in the context of wind energy is analysed regarding the impact of domestic LS, whereby the seasons of the year have been considered. The comparison shown in Fig. 19 demonstrates a decreased probability of energy feedback and high energy consumption. In addition, an increase in the probability regarding low energy consumption has been pointed out. Thus, the qualitative impact of domestic load shifting is similar when comparing the solar energy and wind energy scenario. However, there is a huge quantitative difference when analysing the energy feedback characteristic of both scenarios. The much higher energy feedback of the solar energy scenario is caused by a low load factor of the solar panels because both scenarios consider a total renewable energy ratio of $40 \%$.
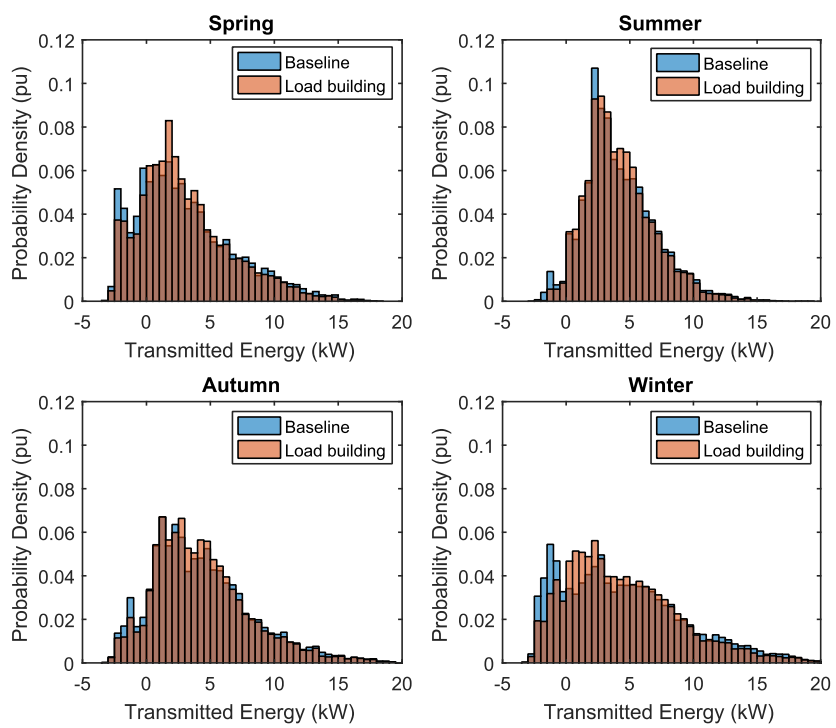

Fig. 19. Comparison of the energy transmission in the context of the wind energy scenario. 


\subsection{Summary}

To summarise, the proposed model has been used to assess the effectiveness of the domestic DSM operating under load shifting algorithm in respect to the type of distributed RES. First, it can be seen that the low load factor of solar energy causes more often high energy feedback. Moreover, it has been demonstrated that a high load factor of the RES is beneficial for energy demand management measures. The summary of the total system behaviour is, therefore, displayed in Fig. 20.

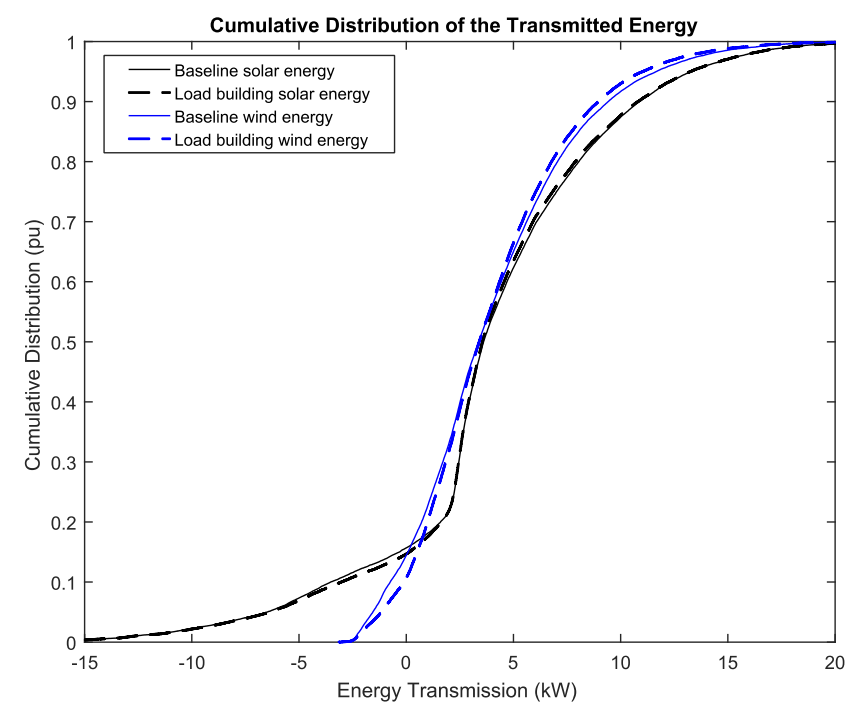

Fig. 20. Comparison of the baseline energy transmission with the demand side management scenario.

Finally, the self-consumption ratio (consumed energy/produced energy) of the analysed scenarios has been calculated in order to determine the impact of the LS implementation. Therefore, the solar energy and wind energy scenarios have been compared regarding the self-consumption ratio. The results are presented in Table 3 .

Table 3. Comparison of the self-consumption ratio.

\begin{tabular}{|l|l|l|}
\hline Scenario & Energy feedback & Self-consumption ratio \\
\hline Solar energy without DSM & $571 \mathrm{kWh}$ & $48.9 \%$ \\
\hline Solar energy with DSM & $539 \mathrm{kWh}$ & $51.77 \%$ \\
\hline Wind energy without DSM & $118 \mathrm{kWh}$ & $89.4 \%$ \\
\hline Wind energy with DSM & $83 \mathrm{kWh}$ & $92.49 \%$ \\
\hline
\end{tabular}

\section{Conclusion}

This paper suggests a high-resolution microgrid model based on historical data of energy consumption and weather conditions. The set of high-resolution historical consumption data is provided by the CLNR. The model can run a high accuracy simulation and represents a UK residential estate comprising of 15 typical UK households. The distribution of the home appliances across the households is based on the real statistical data provided by Northern Powergrid. The model is capable of analysing the performance of the microgrid under the impact of RES (wind or solar) which generate electrical energy according to the realistic historical weather records. The proposed model has been developed as a tool to verify and assess the effectiveness of DSM systems operating under various LS algorithms. Unlike other DSM assessment models usually based on simulated data, the proposed model shows the performance of the system precisely as could be in the real world.

In order to demonstrate the effectiveness of the proposed approach, the model development is underpinned by case study where the DSM operating under a conventional LS algorithm has been assessed. The tested algorithm is based on the criterion of reduction of energy feedback to the feeder to decrease the utilisation of the main grid. The case study comprises of two scenarios according to the type of RES (wind and solar). It has been shown that the self-consumption ratio of the microgrid with the RES is increased by approximately $3 \%$ (Table 3 ) for both scenarios. However, the LS algorithm is slightly more effective in the context of wind energy. 
Moreover, the DSM of domestic appliances contributed to reducing the probability of peak energy demand and feedback, which leads to less energy transmission losses and reduces the utilisation of the grid.

\section{References}

[1] Gellings CW (1981) Power/energy: Demand-side load management: The rising cost of peak-demand power means that utilities must encourage customers to manage power usage. IEEE Spectrum 18(12):4952 .

[2] Gellings CW (1985) The concept of demand-side management for electric utilities. Proc IEEE 73:14681470 .

[3] Eto JH, Koomey JG, McMahon JE, Kahn EP (1988) Integrated analysis of demand-side programs. IEEE Trans Power Systems 3(4):1397-1403.

[4] Wacks KP (1991) Utility load management using home automation. IEEE Trans Consumer Electronics 37(2):168-174.

[5] Siebert LC, Ferreira LR, Yamakawa EK, Custodio ES, Aoki AR, Fernandes TSP, Cardoso KH (2014) Centralized and decentralized approaches to demand response using smart plugs. In: IEEE PES T\&D Conference and Expo, Chicago, IL, USA, 14-17 April 2014, pp 1-5.

[6] Li S, Yang J, Song W, Chen A (2019) A real-time electricity scheduling for residential home energy management. IEEE Internet of Things Journal 6(2):2602-2611.

[7] Afzal M, Huang Q, Amin W, Umer K, Raza A, Naeem M (2020) Blockchain enabled distributed demand side management in community energy system with smart homes. IEEE Access 8:37428-37439.

[8] Bhamidi L, Sivasubramani S (2020) Optimal planning and operational strategy of a residential microgrid with demand side management. IEEE Systems Journal 14(2):2624-2632.

[9] Tsagarakis G, Thomson RC, Collin AJ, Harrison GP, Kiprakis AE, McLaughlin S (2016) Assessment of the cost and environmental impact of residential demand-side management. IEEE Trans Ind Appl 52(3):2486-2495.

[10] Bellarmine G (2000) Load management techniques. In: IEEE Southeast Conference 2000, Nashville, TN, USA, 9 April 2000, pp 139-145.

[11] Barbato A, Capone A (2014) Optimization models and methods for demand-side management of residential users: A survey. Energies 2014(7):5787-5824.

[12] Ran X, Leng S (2019) Enhanced robust index model for load scheduling of a home energy local network with a load shifting strategy. IEEE Access 7:19943-19953.

[13] Jamil M, Mittal S (2020) Hourly load shifting approach for demand side management in smart grid using grasshopper optimisation algorithm. IET Generation, Transmission \& Distribution 14(5):808-815.

[14] Ebrahimi J, Abedini M, Rezaei MM (2020) Optimal scheduling of distributed generations in microgrids for reducing system peak load based on load shifting. Sustainable Energy, Grids and Networks 23:100368

[15] Abdelsalam AA, Zedan HA, El Desouky AA (2020) Energy management of microgrids using load shifting and multi-agent system. Journal of Control, Automation and Electrical Systems (2020) 31:10151036

[16] Ashok S, Banerjee R (2000) Load-management applications for the industrial sector. Applied Energy 66(2):105-111.

[17] Bertineti DP, Canha LN, Medeiros AP, de Azevedo RM, da Silva BF (2019) Heuristic scheduling algorithm for load shift DSM strategy in smart grids and IoT scenarios. In: IEEE PES Innovative Smart Grid Technologies Conference - Latin America, Gramado, Brazil, 15-18 Sept. 2019, pp. 1-6. 
[18] dos Santos LLC, Canha LN, Bernardon DP (2018) Projection of the diffusion of photovoltaic systems in residential low voltage consumers. Renewable Energy 116A:384-401.

[19] Bargauan B, Cretu M, Fati O, Ceclan A, Micu DD, Stet D, Czumbil L (2018) Energy management system for the demand response in TUCN buildings. In: 53rd Int. Universities Power Engineering Conference, Glasgow, UK, 4-7 Sept. 2018, pp. 1-4.

[20] Thiaux Y, Dang TT, Schmerber L, Multon B, Ahmed HB, Bacha S, Tran QT (2019) Demand-side management strategy in stand-alone hybrid photovoltaic systems with real-time simulation of stochastic electricity consumption behavior. Applied Energy, 253:113530.

[21] Stavrakas V, Flamos A (2020) A modular high-resolution demand-side management model to quantify benefits of demand-flexibility in the residential sector. Energy Conversion and Management, 205:112339.

[22] Cretu M, Czumbil L, Bargauan B, Stet D, Ceclan A, Polycarpou A, Rizzo R, Micu DD (2019) Modeling and forecasting energy demand in TUCN buildings. In: International Conference on Clean Electrical Power (ICCEP), Otranto, Italy, 2-4 July 2019, pp. 253-258.

[23] Fischer D, Stephen B, Flunk A, Kreifels N, Lindberg KB, Wille-Haussmann B, Owens EH (2017) Modeling the effects of variable tariffs on domestic electric load profiles by use of occupant behavior submodels. IEEE Trans Smart Grid 8(6):2685-2693.

[24] Facchini A, Rottondi C, Verticale G (2017) Evaluating the effects of social interactions on a distributed demand side management system for domestic appliances. Energy Efficiency 10(5):1175-1188.

[25] McKenna E, Thomson M (2014) Demand response behaviour of domestic consumers with photovoltaic systems in the UK: An exploratory analysis of an internet discussion forum. Energy, Sustainability and Society $4: 13$.

[26] Vlot MC, Knigge JD, Slootweg JG (2013) Economical regulation power through load shifting with smart energy appliances. IEEE Trans Smart Grid 4(3):1705-1712.

[27] Liu M, Quilumba FL, Lee W-J (2015) A collaborative design of aggregated residential appliances and renewable energy for demand response participation. IEEE Trans Ind Appl 51(5):3561-3569.

[28] Costanzo GT, Zhu G, Anjos MF, Savard G (2012) A system architecture for autonomous demand side load management in smart buildings. IEEE Trans Smart Grid 3(4):2157-2165.

[29] Wang Y, Yang W, Liu T (2017) Appliances considered demand response optimisation for smart grid. IET Generation Transmission and Distribution 11(4):856-864.

[30] Sun Q, Li H, Ma Z, Wang C, Campillo J, Zhang Q, Wallin F, Guo J (2016) A comprehensive review of smart energy meters in intelligent energy networks. IEEE Internet of Things Journal 3(4):464-479.

[31] Vivekananthan C, Mishra Y, Ledwich G, Li F (2014) Demand response for residential appliances via customer reward scheme. IEEE Trans Smart Grid 5(2):809-820.

[32] Khan I (2019) Energy-saving behaviour as a demand-side management strategy in the developing world: The case of Bangladesh. Int Journal Energy and Environmental Engineering 10(4):493-510.

[33] Facchini A, Rottondi C, Verticale G (2017) Evaluating the effects of social interactions on a distributed demand side management system for domestic appliances. Energy Efficiency 10(5):1175-1188.

[34] Arun SL, Selvan M P (2018) Intelligent residential energy management system for dynamic demand response in smart buildings. IEEE Systems Journal 12(2):1329-1340.

[35] Meyabadi AF, Deihimi MH (2017) A review of demand-side management: Reconsidering theoretical framework. Renewable and Sustainable Energy Reviews 80:367-379.

[36] Almehizia AA, Al-Masri HMK, Ehsani M (2019) Integration of renewable energy sources by load shifting and utilizing value storage. IEEE Trans on Smart Grid 10(5):4974-4984. 
[37] Mehta R, Srinivasan D, Verma P (2017) Intelligent appliance control algorithm for optimizing user energy demand in smart homes. In: IEEE Congress on Evolutionary Computation (CEC), San Sebastian, Spain, 5-8 June 2017, pp. 1255-1262.

[38] Ozturk Y, Senthilkumar D, Kumar S, Lee G (2013) An intelligent home energy management system to improve demand response. IEEE Trans Smart Grid 4(2):694-701.

[39] Abushnaf J, Rassau A (2019) An efficient scheme for residential load scheduling integrated with demand side programs and small-scale distributed renewable energy generation and storage. Int Trans Electrical Energy Systems 29(2):e2720.

[40] Martirano L, Habib E, Parise G, Greco G, Manganelli M, Massarella F, Parise L (2017) Demand side management in microgrids for load control in nearly zero energy buildings. IEEE Trans Ind Appl 53(3):1769-1779.

[41] Wu Z, Tazvinga H, Xia X (2015) Demand side management of photovoltaic-battery hybrid system. Applied Energy 148:294-304.

[42] Lin UH (2019) Novel smart home system architecture facilitated with distributed and embedded flexible edge analytics in demand-side management. Int Trans Electrical Energy Systems 29(6):e12014.

[43] Javaid N, Ullah I, Akbar M, Iqbal Z, Khan FA, Alrajeh N, Alabed MS (2017) An intelligent load management system with renewable energy integration for smart homes. IEEE Access 5:13587-13600.

[44] Customer-Led Network Revolution (2014) Project data. http://www.networkrevolution.co.uk/resources/project-data/

[45] Statista (2016) Percentage of households with dishwashers in the United Kingdom (UK) from 1994 to 2016. https://www.statista.com/statistics/289151/household-dishwashing

[46] Statista (2014) Percentage of households with tumble dryers in the United Kingdom (UK) from 1995 to 2014. https://www.statista.com/statistics/289140/tumble-dryers-in-households-in-the-uk

[47] Statista (2014) Percentage of households with washing machines in the United Kingdom (UK) from 1970 to 2014. https://www.statista.com/statistics/289017/washingmachine-ownership-in-the-uk

[48] Department of Energy \& Climate Change (2015) Energy consumption in the UK (2014). http://wwwhome.cs.utwente.nl/ toerscheha/phd/mirror/EnergyConsumptionUK2014.pdf

[49] OVO Energy Ltd (2015) How much electricity does a home use? https://www.ovoenergy.com/guides/energy-guides/how-much-electricity-does-a-home-use.html

[50] Richardson I, Thomas M, Infield D (2008) A high-resolution domestic building occupancy model for energy demand simulations. Energy and Buildings 40(8):1560-1566.

[51] Centre for Environmental Data Analysis (2016) Midas: Global radiation observations. http://data.ceda.ac.uk/badc/ukmo-midas/data/RO/

[52] Centre for Environmental Data Analysis (2016) Midas: UK mean wind data. http://data.ceda.ac.uk/badc/ukmo-midas/data/WM/

[53] Praveen J, Ramaraju VV (2017) Materials for optimizing efficiencies of solar photovoltaic panels. Materials Today: Proceedings 4(4)D:5233-5238.

[54] Pandey A, Tyagi V, Selvaraj JA, Rahim N, Tyagi S (2016) Recent advances in solar photovoltaic systems for emerging trends and advanced applications. Renewable and Sustainable Energy Reviews 53:859-884.

[55] Ubertini S, Desideri U (2003) Performance estimation and experimental measurements of a photovoltaic roof. Renewable Energy 28:1833-1850.

[56] Teschner N, Alterman R (2018) Preparing the ground: Regulatory challenges in siting small-scale wind turbines in urban areas. Renewable and Sustainable Energy Reviews 81(2):1660-1668. 